\title{
DESIGNING OF MEMBRANE CONTACTORS WITH CROSS-COUNTER CURRENT FLOW
}

\author{
Andrzej B. Kołtuniewicz ${ }^{*}$, Szymon Modelski ${ }^{2}$ and Anna Witek ${ }^{2}$ \\ ${ }^{1}$ Warsaw University of Technology, Faculty of Chemical and Process Engineering, Waryńskiego 1, \\ 00-645 Warszawa, Poland \\ ${ }^{2}$ Wroclaw University of Technology, Faculty of Chemistry, Norwida 4/6, 50-373, Wroclaw, Poland
}

\begin{abstract}
The knowledge about membrane contactors is growing rapidly but is still insufficient for a reliable designing. This paper presents a new type of membrane contactors that are integrated with one of the following ways of separation by using absorbents, micelles, flocculants, functionalized polymers, molecular imprints, or other methods that are based on aggregation. The article discusses methods for designing multi-stage cascade, usually counter-current. At every stage of this cascade, relevant aggregates are retained by the membrane, while the permeate passes freely through membrane. The process takes place in the membrane boundary layer with a local cross-flow of the permeate and the retentate. So the whole system can be called a cross-counter-current. The process kinetics, $k$, must be coordinated with the permeate flux, $J$, and the rate of surface renewal of the sorbent on the membrane surface, $s$. This can be done by using ordinary back-flushing or relevant hydrodynamic method of sweeping, such as: turbulences, shear stresses or lifting forces. A surface renewal model has been applied to adjust the optimal process conditions to sorbent kinetics. The experimental results confirmed the correctness of the model and its suitability for design of the new type of contactors.
\end{abstract}

Keywords: membrane contactors, sorption processes, integrated processes of separation, designing, surface renewal theory

\section{INTRODUCTION}

A key concept for the use of membrane in contactors as artificial surface between the phases for the purpose of the processes of mass or heat transfer (Drioli and Giorno, 2005). Although the physical mechanisms are essentially the same, as in classical unit processes, they are generally much less dependent on fluid dynamics and relevant problems. Conventional unit processes, e.g. distillation extraction, absorption have large process constrains. These are high pressure drops, high energy consumption, a narrow range of performance, several disturbances as entrainment, weeping, mixing, emulsification, foaming, etc. Membrane contactors are involved in process intensification defined by Stankiewicz and Moulijn (2004), as "...the development of novel apparatuses and techniques that, compared to those commonly used today, are expected to bring dramatic improvements in manufacturing and processing, substantially decreasing equipment-size/production-capacity ratio, energy consumption, or waste production, and ultimately resulting in cheaper, sustainable technologies." Currently, eight types of well-known contactors found commercial applications, namely: membrane scrubbers, strippers, extractors, distillers (with regard to osmotic distillation), emulsifiers, supported liquid membranes and reactors for phase transfer catalysis. However, many other types have not as yet found practical application in accordance with an "open definition" of contactors by Drioli

*Corresponding author, e-mail: A.Koltuniewicz@ichip.pw.edu.pl 
and Giorno (2005): "All operations that are based on the mass transport between two contacting phases can be in principle carried out by membrane contactors". The importance of integrated membrane processes in sustainable technologies was presented in the literature (Koltuniewicz and Drioli, 2008; Koltuniewicz, 2010; Koltuniewicz, 2011). The new contactors such as membrane adsorption were discussed in detail by (Koltuniewicz et al., 2004) with its specific case of the membrane biosorption (Koltuniewicz and Bezak, 2002). The main idea of the practical application of biosorption is the use of waste materials that can be reused according to the idea of sustainable development and clean technologies. The function of the membrane is a mechanical separation of finely powdered sorbents in aqueous suspensions. Biosorption mechanisms are similar to ordinary adsorption with a high percentage of ion exchange. Another example for membrane sorption was an integrated process using $\mathrm{N}$-methyl glucamine chelating resins with submerged microfiltration membrane for removal of resin-boron complexes (Yilmaza et al., 2004). In a series of articles the effects of micelles supporting the performance of contactors during removal of xenobiotic with membrane extraction (Witek et al., 2006, 2009) as well as membrane absorption (Modelski et al., 2011) were presented. Membrane contactors success is due to the fact that they can be easily retrofitted to conventional industrial technologies leading to considerable reduction of energy consumption and feasibility, or compliance with increasingly stringent environmental requirements. This was made possible through a development of nanotechnology and materials science necessary to produce a membranes (Drioli and Giorno, 2005).

\section{DESIGNING OF THE CO-CURRENT AND COUNTER-CURRENT CONTACTORS}

The Membrane contactor consists of a membrane that two flow regions allows separation between the two phases, where mass transport takes place. The membrane acts as a barrier between the two fluid phases and selectively allows or prohibits the transport of one or more chemical species or particles from one fluid stream to the other. Membranes with specific properties should be used for contactors of membranes, e.g.: microporous with uniform pores and/or composite which can be hydrophobic/hydrophilic, symmetric/asymmetric, and dense/microporous. Pore size distribution should be as sharp as possible in order to protect against exceeding the breakthrough pressure, which can be calculated from a modified Young-Laplace equation:

$$
\Delta P=\frac{2 \cdot \sigma \cdot \cos (\theta)}{d}
$$

A plant construction containing membrane contactors is very simple because of the modularity and linear scale-up. Assuming that the plant operates uniformly along the entire length, $L$, and that it uses counter current flow of phases (see Fig. 1), the following balance equation can be written:

$$
v_{0} \ln c_{i}-v_{0} \ln c_{o}=k \cdot a \cdot L
$$

Based on this equation, one can precisely calculate the required number of membrane modules to ensure effective separation. A typical system consists of a cascade of membrane modules connected in series counter-currently, to ensure maximum driving force of the process. However, in some cases, system shall be co-current (Fig 1a). Such cases occur when the flow resistances of the media are too large or the membranes are of poor quality (too high wettability, far too large pores or too diffuse distribution of their size).

Overall mass transfer coefficient can be calculated after the calculation of the local mass transfer coefficients on both sides of the membrane $k_{1}$ and $k_{2}$ as well as in the membrane, according to the following equation (Eq. 3): 


$$
\frac{1}{k_{o v}}=\frac{1}{k_{1}}+\frac{1}{k_{m}}+\frac{K}{k_{2}}
$$

where $K$ is the equilibrium constant, appropriate for a particular system in which the relevant phase 1 and 2 are defined as gas-liquid (in membrane absorption) or liquid-liquid (for membrane extraction or membrane distillation). An adequate arrangement of the two phases relative to the membrane must be ensured, i.e., which phase flows inside the capillary (inside tube) or outside (shell side). A model takes into account the general case where resistances in both phases are approximately equal. Usually, in specific cases, resistance in one phase is dominant. Then, we consider only the resistance of this phase and the resistance of the membrane, which can be determined by Wilson method discussed in many publications on membrane contactors (e.g. Koltuniewicz, 2010). During calculations, mass transfer coefficient in the membrane must take into account the effective diffusion coefficient, which may differ considerably from physical diffusivity.

$$
k_{m}=\frac{D_{e f}}{\delta_{e f}}=\frac{D_{m} \cdot \varepsilon_{m}}{\delta_{m} \cdot \tau_{m}}
$$

This may be due to tortuosity, porosity and incomplete filling volume of membrane pores. Consequently, the diffusion path is not equal to the thickness of the membrane and the surface of mass transfer is smaller than the membrane surface due to its porosity. The pore size distribution in membrane is another reason for relevant inaccuracies. A variable diameter of the pores can lead to excess of the "breakthrough pressure" (see Young-Laplace formula, Eq. 1) in the larger pores of the membrane. This in turn can lead an uneven filling of the pores of phases 1 and 2 depending on the pressure distribution in the module. This phenomenon may be more pronounced at high hydraulic resistance and/or a large number of degrees in a cascade of membrane modules working in a counter current system.

It should be noted that during designing, the engineer can (to some extend) affect the value of the overall mass transfer coefficient through the appropriate selection of flow-rates and to proper choice of membrane properties. The rule is to keep the phase in which we expect a larger resistance of mass transfer on the outer membrane (shell side). Membrane resistance is the inverse of the mass transfer coefficient, which may be calculated from one of the two equations presented in the book (Reed et al., 1995):

- for shell (outer) side of the membrane:

$$
S h_{1}=\frac{k_{1} \cdot d_{1}}{D_{1}}=1.4 \cdot\left(\frac{d \cdot v_{1}}{D_{1}}\right)^{1 / 3}
$$

- for the lumen (internal) side of the capillary membrane (Leveque formula):

$$
S h_{2}=\frac{k_{2} \cdot d_{2}}{D_{2}}=1.62\left(\frac{d_{2}^{2} \cdot v_{2}}{L_{2} \cdot D_{2}}\right)^{1 / 3}
$$

Here, subscripts 1 and 2 refer respectively to the two phases. It should be noted that phase flows can be optimised in terms of kinetics, membrane surface or overall costs of the entire plant. In this case, the hydrodynamic limits as the pressure drops and the associated breakthrough of the membrane must be taken into account. When these optimised flows $(v 1$ and $v 2)$ are different than those resulting previously from the feeds assumed at the beginning of the calculations, recirculation is used at each stage of the cascade plant. Then the flow rate required to maximise the performance of the contactor is called an "excess sweep". 
The cross-counter-current configuration may be used, for development of the new integrated processes based on the contact of the solid and liquid phases at appropriate membrane surface, which will be discussed in the next part.

a)
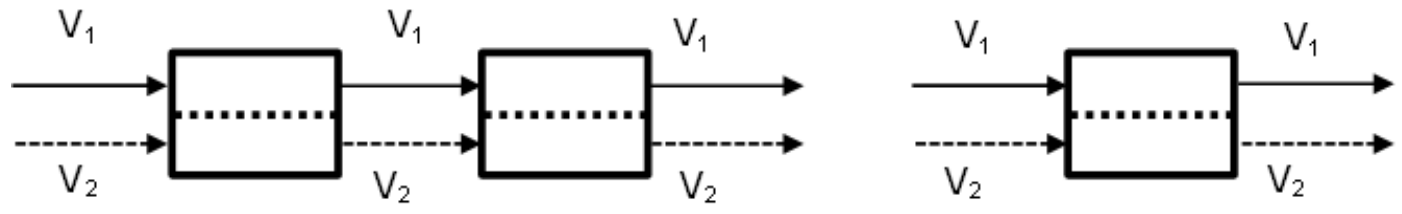

b)
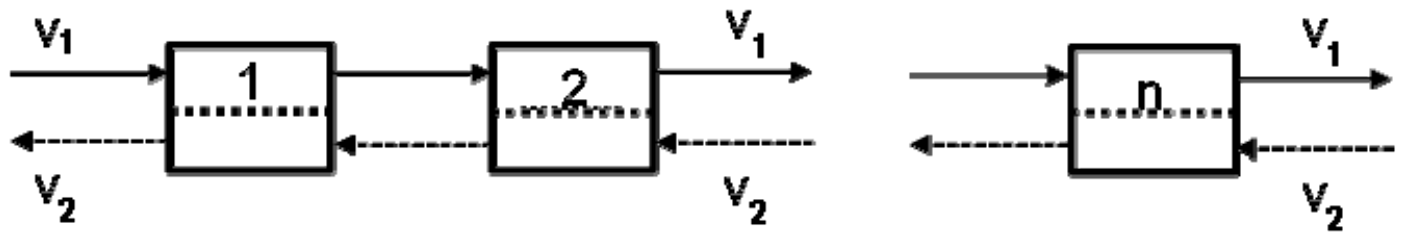

c)
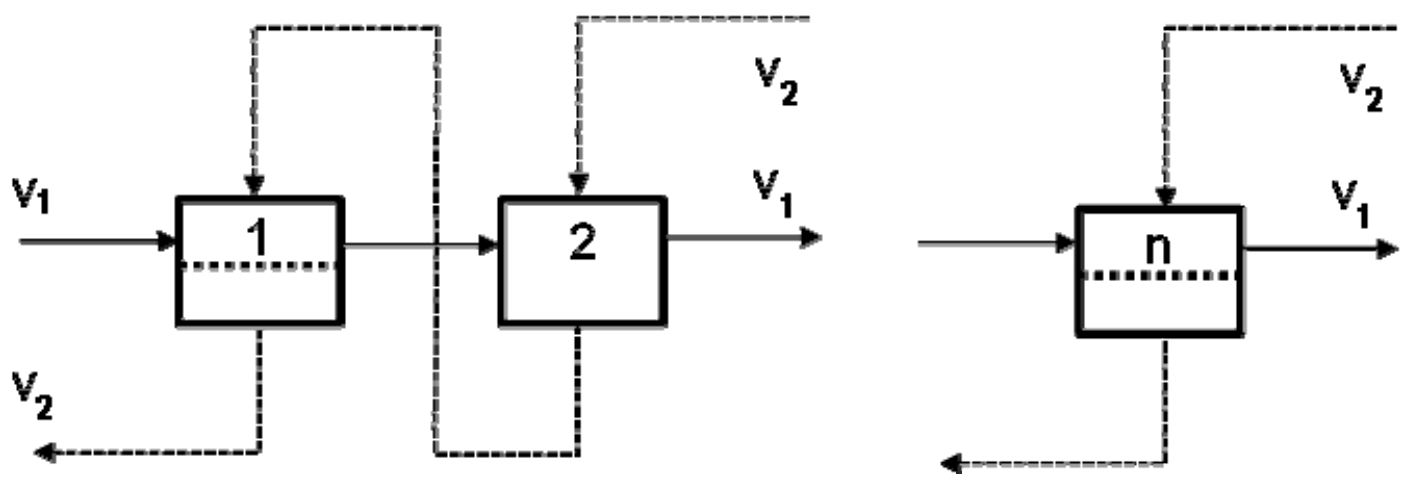

Fig. 1. Configurations of membrane modules in the contactors systems: a) co-current flow, b) counter-current flow, c) cross-counter current flow

\section{DESIGNING CROSS-COUNTER-CURRENT CONTACTORS}

A new type of an integrated process was designed to increase the productivity and efficiency of separation, which involves the creation of larger aggregates prior to their separating on the membrane. During the separation of these larger aggregates, the flux is much larger and the flow resistance is lesser, and consequently, membrane separation becomes more efficient and cheaper. To increase the size of separated particulates or molecules, the following ways of aggregation are used :

- adsorption on pulverised adsorbent,

- biosorption on microorganisms,

- complexation, chelation,

- binding on functionalized polymers,

- binding on ion exchange resins,

- binding on molecularly imprinted materials,

- coagulation, flocculation,

- precipitation,

- micellar solubilisation, etc. 
In leaching, physical, chemical or biological sorption; ion exchange, the membrane allows to use grains with a high degree of dispersion, and the only limit is the cost of such disintegration processes. The benefit of much dispersed grains is a larger contact surface (specific surface $a=1 / d$ ), which improves orption uptake, an increase of sorption kinetics due to the shortened diffusion paths. Inside the singular stage of a cascade (Fig. 1c), the retentate containing a suspension of such aggregates flows parallel to the membrane surface and permeate passes through the membrane in a direction perpendicular to its surface without particles or aggregate. During a relevant process, the liquid passes through the filter cake layer formed of aggregates retained on the membrane surface. This is the place where the appropriate physical or chemical processes occur much faster than in the bulk of the retentate stream. The reason is the increased concentration of sorbents, catalyst, the micelles, etc., in comparison to the bulk. But the main problem is a small volume of a thin film formed in the vicinity of the membrane and immobility, which facilitates its rapid saturation. However, it is possible to permanently remove aggregates from the surface of the membrane after strictly defined time using well known methods to reduce the polarisation layer. However first one has to check whether membrane $s$ were chosen correctly and whether aggregates form a cake (which is proper), or simply block the membrane pores. This can be done, by using the following formula (Eq. 7) (Koltuniewicz and Field, 2004):

$$
J(t)=\left[J_{0}^{n-2}-k \cdot A^{2-n} \cdot(n-2) \cdot t\right]^{\frac{1}{n-2}}
$$

Where $A$ is the membrane surface, $J$ is the permeate flux, $t$ is the current time and the $k$, and $n$ are the parameters. After an experimental determination of flux decline $J(t)$ in time, under certain process conditions one can identify the parameter $n$ in Eq. (7). If the value of $n$ is close to zero (a good case), then there is a cake on the membrane surface, but when it is close to 2 (poor case), then pores are blocked at membrane and a membrane with smaller pores must be chosen. In the case of "cake" microfiltration, appropriate conditions of retentate flow (tangentially to the membrane surface) can be applied to remove the cake with the specified rate. The rate of renewal of the membrane surface can be determined from the experimental formulas (Koltuniewicz, 1992; Koltuniewicz and Field, 1996):

$$
s=m \cdot u^{n}
$$

Where $u$ is an average axial velocity of the fluid in membrane module, and the parameters $m$ and $n$ (in Eq. 8) can be determined from Table 1.

Table 1. Experimentally determined parameters for calculation of surface renewal rate

\begin{tabular}{|c|c|c|}
\hline Module type & Constant $m$ & Constant $n$ \\
\hline plate and frame (slot $0.15 \mathrm{~m} \times 0.001 \mathrm{~m})$ & 0.00074 & 0.75 \\
\hline tubular ceramic $\left(\right.$ Membralox ${ }^{\circledR} 19$ tubes) & 0.0020 & 0.80 \\
\hline capillary (Romicon ${ }^{(}(d=1 \mathrm{~mm})$ & 0.0035 & 0.66 \\
\hline
\end{tabular}

The rate of surface renewal can be also evaluated using Einstein and Lee (1956) formulae (Eq. 9):

$$
s=0.392 \cdot f \cdot \frac{\tau}{\rho \cdot \mu}
$$

Where: $f$ - fanning factor, $\tau$ - shear stress, $\rho$ - liquid density and $\mu$ - viscosity. Considering the critical flux model, the sorbent residence time at the membrane surface (on retentate side) can be also controlled. Then flux must be lower than the lateral migration velocity (Eq. 10):

$$
u_{y 0}=0.577 \cdot \frac{\rho \cdot r^{3} \cdot \gamma^{2}}{16 \mu}
$$


Where: $r$ - particle dimension (radius), $\gamma$ - the shear rate, $\rho$ - liquid density and $\mu$ - viscosity. In any case, the back-flushing may also be used to remove sorbent from membrane surface with a given rate to control adequately the kinetics of sorption.

\section{EQUILIBRIUM AND KINETICS OF MEMBRANE SORPTION}

For further analysis there is a need to focus on a particular process, which may be called a membrane sorption process. Equilibrium sorption isotherms are shown in Table 2. The Langmuir isotherm is frequently applied, because of its universal character describing not only the physical adsorption but generally the binding of a solute, to the active sites of sorbent. Sorption isotherms, describing the equilibrium are shown in Table 2.

Table 2. Isotherms of equilibrium of the biosorption process (Pagnanelli et al., 2003)

\begin{tabular}{|c|c|}
\hline Isotherm & Equation \\
\hline Langmuir & $q=q_{\max } \cdot \frac{b \cdot C}{1+b \cdot C}$ \\
\hline Freundlich & $q=k \cdot C^{\frac{1}{n}}$ \\
\hline Langmuir-Freundlich & $q=q_{\max } \cdot \frac{b \cdot C^{\frac{1}{n}}}{1+b \cdot C^{\frac{1}{n}}}$ \\
\hline Radke and Prausnitz & $\frac{1}{q}=\frac{1}{a \cdot C}+\frac{1}{b \cdot C^{n}}$ \\
\hline Reddlich-Peterson & $q=\frac{a \cdot C}{1+b \cdot C^{n}}$ \\
\hline
\end{tabular}

The kinetics with which the process works is very important for engineering aspects and practical reasons. Usually it is assumed that the rate of saturation of the active sites of sorbent is a reaction of the first order or pseudo-first order. Then one can determine the kinetic constant, $k$, of the sorbent during the sorption time based on the formulas in Table 3.

Table 3. Kinetic equations of the biosorption process (Pagnanelli et al., 2003)

\begin{tabular}{|c|c|}
\hline Reaction type & Equation \\
\hline First-order reaction & $q(t)=q^{*} \cdot\left(1-e^{-k \cdot t}\right)$ \\
\hline Pseudo-second order reaction & $q(t)=\frac{t}{\frac{1}{k \cdot q^{*}}+\frac{t}{q^{*}}}$ \\
\hline
\end{tabular}


A component of the solution is adsorbed during the flow through the sorbent layer situated on the membrane. If this layer is regenerated $\left(q_{0} \neq 0\right)$, then the concentration of solute in the sorbent can be calculated from the formula:

$$
q(t)=q^{*}-\left(q_{0}-q^{*}\right) \cdot e^{-k t}
$$

The concentration in the permeate flowing out from the sorbent layer can be calculated from the mass balance of the solute in an open system including local permeate flow through the layer in which there is a partial accumulation of the solute system from the formula (Koltuniewicz and Bezak, 2002; Koltuniewicz et al., 2004)

$$
C_{P}(t)=C_{R}-\frac{k \cdot X_{m} \cdot \delta \cdot\left(q^{*}-q_{R}\right)}{J-k \cdot \delta} \cdot\left[e^{-k t}-e^{-\frac{J}{\delta} t}\right]
$$

As shown above (see Eq. 12 and Fig. 2), concentration in the permeate decreases initially from initial concentration $C_{R}$, then after reaching the minimum $C_{P}^{\min }$, to grow with the progress of saturation of the sorbent, reaching at last the concentration $C_{R}$ at the incoming retentate. Time $t\left(C_{P}^{\min }\right)$ after which the concentration of the permeate reaches the minimum value, indicates the need to exchange the sorbent layer. Biosorption ceases, when concentration of the solute in biosorbent reaches equilibrium with respect to the concentration in the retentate, $C_{R}$.

$$
t\left(C_{P}^{\min }\right)=\frac{\ln \left(\frac{k \delta}{J}\right)}{k-\frac{J}{\delta}}
$$

Equation (Eq. 13) can be used to determine the time between successive cycles of back-flushing. This case assumes that the sorbent layer on the membrane is immobile but homogenous with a constant thickness, $\delta$.

\section{RENEWAL OF MEMBRANE BOUNDARY LAYER}

Membrane sorption can also be carried out without back-flushing due to permanent renewal of sorbent layer at a membrane surface. A proper choice of process conditions enables to select of optimal values of the surface renewal rate (Eq. 18), which maintains a minimum concentration in permeate at a constant level, for a long time (Koltuniewicz et al., 2004). For this purpose the theory of surface renewal by Danckwerts may be used. According to the surface renewal theory, the entire surface of the membrane is covered with infinitely small fragments with different "ages" from zero to infinity. Practically, the age of the oldest element of can never exceed $t_{p}$ the real time of the process itself i.e., from the start. This is due to the stochastic action of eddies that penetrate the membrane surface randomly at any time and place. Then the membrane is covered with a mosaic of elements of the sorbent and the concentration of permeate has an average value of the local concentration $C(t)$ consistent with age distribution of those elements $f(t)$.

$$
C_{P}^{m}=\int_{0}^{t_{P}} C(t) \cdot f(t) \cdot d t
$$

The local concentration can $C(t)$ is calculated from Eq. 12. The age distribution function after Danckwerts was modified by (Koltuniewicz, 1992), who made the assumption that the age of the oldest element age cannot exceed the duration of the process. Then he gave another form of this function 
where the age is dependent on the duration of the process ( $t p)$ taking into account the possibility of "aging" of surface elements.

$$
f(t)=\frac{s \cdot e^{-s t}}{1+e^{-s t_{p}}}
$$

But after infinite time, both functions are converging. After integrating (Eq. 14), followed by substituting (Eq. 12) and (Eq. 15), the equation (Eq. 16) is obtained as a result. This allows to determine the average solute concentration in the permeate passing through the membrane and cake, in the real-time of the process, $t_{p}$ :

$$
C_{P}^{m}=C_{R}-\left[\frac{1-e^{-(k+s) \cdot t_{p}}}{k+s}-\frac{1-e^{-\left(\frac{J}{\delta}+s\right) \cdot t_{p}}}{\frac{J}{\delta}+s}\right] \cdot \frac{k \cdot X_{m} \cdot \delta \cdot\left(q^{*}-q_{R}\right)}{J-k \cdot \delta} \cdot \frac{s}{1-e^{-s \cdot t_{p}}}
$$

Eq. (16) describes changes in concentration of permeate during process time, $t_{p}$, due to "ageing" (i.e., saturating) of the elements' population on the membrane surface. Since the age distribution approaches the stable distribution after a long-time process, the concentration in permeate will be time independent and it approaches the constant asymptotic value:

$$
C_{P}^{m}=C_{R}-X_{m} \cdot\left(q^{*}-q_{R}\right) \cdot \frac{k \cdot \delta \cdot s}{(J+s \cdot \delta) \cdot(k+s)}
$$

The best hydrodynamic conditions in the module could be determined using the optimal rate of surface renewal which can be derived from Eq. (18):

$$
s_{\text {opt }}=\sqrt{\frac{k \cdot J}{\delta}} \text { for } C_{P}^{\min } \text { when } \frac{d C_{P}^{m}}{d s}=0
$$

The mathematical model has been confirmed many times during membrane biosorption and adsorption studies (Koltuniewicz and Bezak, 2002; Koltuniewicz et al., 2004; Witek et al.. 2006; 2009). But the most spectacular finding was the application of the model to describe the MEU (micelle enhanced ultrafiltration), which can be described as a special kind of integrated process with micellar aggregation. In this case, the model allowed to confirm, two theses. The first was the experimental confirmation of the model suitability for a generalized description of various membrane sorptions. The second objective of this experiment was to document the suitability the membrane in the process of micellar solubilisation of cresol.

\section{EXPERIMENTAL}

The above mentioned apparatus, i.e. membrane contactor can be applied to several different processes that are listed in paragraph 3 of this article. Experimental verification of the model was carried out on the example of micellar solubilisation of cresol, followed by membrane separation of aggregates. The trials were carried out with polysulphone ultrafiltration membrane which does not reject cresol. However, the formation of micelles in this case, explains the visible effect of cresol retention. The micelles were formed at the surface of the membrane due to concentration polarization, although in the bulk of the retentate, surfactant concentration was below the CMC. In this way, it was possible to keep the formation of micellar aggregates within the retentate, based on the presence of cresol within the permeate. The feed solution was prepared by mixing desired amounts of surfactant below CMC and p-cresol (p-cresol, $\mathrm{C}_{7} \mathrm{H}_{7} \mathrm{ClO} M=142.6$ POCh Gliwice) with concentration of $0.1 \%$ mass. The experiments were conducted in a dead-end system using the surfactant $\mathrm{CTAB}\left(\mathrm{C}_{19} \mathrm{H}_{42} \mathrm{BrN}, M=364.45\right.$, 
$\mathrm{CMC}=1 \mathrm{mM} / \mathrm{l})$ with different concentrations $(C=0.113 \mathrm{mM}$ and $C=0.101)$ but far below $\mathrm{CMC}=1 \mathrm{mM}$. The concentrations of surfactant CTAB were analysed by UV/VIS spectrophotometer (Schimadzu UV-160A) at wavelength of $525 \mathrm{~nm}$. The concentration of p-cresol was analysed using gas chromatography (Schimadzu GC14A). Normally, aggregates are formed after exceeding CMC (critical micelle concentration). In this case, concentration of surfactant is smaller (one order of magnitude lesser than $\mathrm{CMC}$ ), but at the membrane surface it exceeds the $\mathrm{CMC}$, allowing the formation of micelles and, consequently, the retention of cresol. However, for a higher surfactant concentration the higher separation effect was visible, which indicates a greater number of a micelles. Separation of micellar aggregates of cresol on the membrane, indicate a distinct, but temporary effect of separation, because the "saturation" of surfactant (above CMC concentration) at the membrane surface. Similar observations were reported in many other membrane-assisted integrated processes, such as biosorption, adsorption, ion exchange, etc. The effect of saturation can be seen on the membrane surface in membrane reactors, especially with a deficit of catalyst in the reactor bulk. Here, the role of the membrane may be to increase the concentration of sorbent, resin and catalyst. However, in the case of sorption or reaction that takes place in thin layers near the membrane surface, saturating effect of such small layers is visible. This creates the need for renewal of these layers in a given time and a fixed rate and can be done using the methods and models presented in this article.

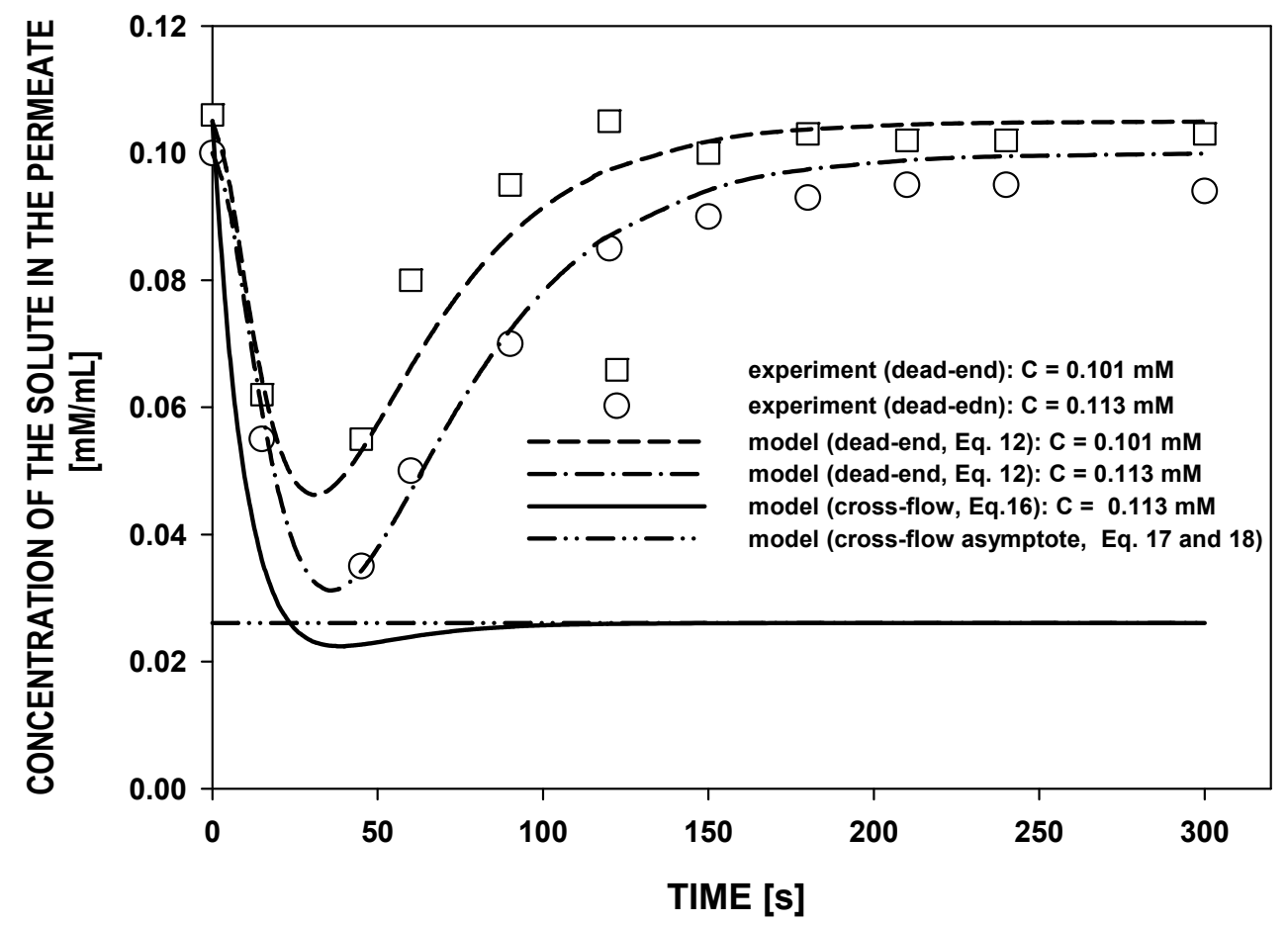

Fig. 2. Effect of membrane separation of micellar aggregates of cresol below CMC in the bulk. $J=10 \mathrm{LMH}, k=2.75 \mathrm{~s}^{-1}, q^{*}=0.1 \mathrm{~g}$ met $/ \mathrm{g}$ sorb, $X_{m}=6 \mathrm{~g}$ sorb/l sol, $\delta=2.8 \mu \mathrm{m}, s_{\text {opt }}=0.505 \mathrm{~s}^{-1}$

\section{CONCLUSIONS}

- The new separation processes based on the two steps, i.e.: 1) aggregation of particles with different methods, then followed by 2) membrane separation, may be classified as integrated membrane processes and they can be conducted in membrane contactors. Such processes may include: adsorption on pulverised adsorbent, biosorption on microorganisms or pulverised biomass, complexation, chelation, binding on functionalized polymers, binding on pulverised ion exchange resins, molecularly imprinted materials, and many others such as membrane enhanced coagulation, flocculation, precipitation, crystallization, and micellar solubilisation, etc. 
- The new class of separation processes can be performed by means of membrane contactors working in multistage "cross-counter-current" systems. The whole system is counter current whereas the cross-flow is in each stage. The application of very fine particles enhances equilibrium and kinetics of membrane sorption.

- The usefulness of surface renewal theory for the description of (cross-counter-current) membrane contactors working in the liquid-solid was confirmed in this article (see Fig. 2).

\section{SYMBOLS}

$\begin{array}{ll}a & \text { surface area, } \mathrm{m}^{2} / \mathrm{m}^{3} \\ C & \text { concentration of the solute in the fluid, } \mathrm{kg} / \mathrm{m}^{3} \\ D & \text { diffusion coefficient, } \mathrm{m}^{2} / \mathrm{s} \\ \mathrm{d} & \text { diameter, } \mathrm{m} \\ f(t) & \text { age function, } \\ f & \text { friction coefficient }(\text { Fanning factor) } \\ J & \text { permeate flux, } \mathrm{m} / \mathrm{s}=\mathrm{m}^{3} /\left(\mathrm{m}^{2} \mathrm{~s}\right) \\ K & \text { equilibrium constant } \\ k & \text { kinetic constant, } \mathrm{s}^{-1} \\ k & \text { mass transfer coefficient, } \mathrm{m} / \mathrm{s} \\ L & \text { length of the total cascade of contactors. } \\ m, n & \text { constants at Eq. } 7,8 \text { and Table } 1 \\ \Delta P & \text { breakthrough pressure, Pa } \\ S & \text { the rate of surface renewal, } \mathrm{s}^{-1} \\ q & \text { sorption uptake, } \\ t & \text { time, } \\ v & \text { velocity of the fluid, } \mathrm{m} / \mathrm{s} \\ X & \text { concentration of the sorbent, } \mathrm{kg} / \mathrm{m}^{3}\end{array}$

Greek symbols

$\delta \quad$ thickness of the membrane,

$\varepsilon \quad$ porosity, dimensionless

$\gamma \quad$ shear rate, $\mathrm{s}^{-1}$

$\mu \quad$ liquid viscosity, $\mathrm{kg} /(\mathrm{m} \mathrm{s})$

$\rho \quad$ liquid density, $\mathrm{kg} / \mathrm{m}^{3}$

$\sigma \quad$ surface tension of the liquid, $\mathrm{N} / \mathrm{m}$

$\tau$ tortuosity factor, dimensionless

$\tau \quad$ shear stress, $\mathrm{Pa}$

$\theta \quad$ contact angle, rad

\section{Superscripts}

$(1,2, \ldots, n)$ number of stage

$(*) \quad$ equilibrium value

$m \quad$ mean value

Max maximum value

Min minimum value

\section{Subscripts}

1,2 number of component

$h \quad$ hydraulic (diameter)

$i \quad$ at the inlet 
at the outlet

$v \quad$ overall

$m$ membrane

$P \quad$ permeate

$R \quad$ retentate

\section{REFERENCES}

Ding H.B., Carr P.W., Cussler E.L., 1992. Racemic leucine separation by hollow-fiber extraction. AIChE J., 38, 1493-1498. DOI: DOI: 10.1002/aic.690381002.

Drioli E., Giorno L., 2005. Membrane Contactors: Fundamentals, $1^{\text {st }}$ edition, ELSEVIER.

Commercial Brochure of Liqui Cel ${ }^{\circledR}$, Membrana, 2012. North Carolina, USA.

Einstein H.A., Li H., 1956. The viscous sublayer along a smooth boundary. J. Eng. Mech. Div. ASCE, 82, EM2.

Koltuniewicz A.B., 1992. Predicting permeate flux in ultrafiltration on the basis of surface renewal concept. J. Membrane Sci., 68, 107-118. DOI: 10.1016/0376-7388(92)80153-B.

Koltuniewicz A.B., Field R.W., 1996. Process factors during removal of oil-in-water emulsions with cross-flow microfiltration. Desalination, 105, 79- 89. DOI: 10.1016/0011-9164(96)00063-X.

Koltuniewicz A.B., Bezak K., 2002. Engineering of membrane biosorption. Desalination, 144, 219-226. DOI: 10.1016/S0011-9164(02)00315-6.

Koltuniewicz A.B., Witek A., Bezak K., 2004. Efficiency of membrane-sorption integrated processes. J. Membrane Sci., 239, 129-141. DOI: 10.1016/j.memsci.2004.02.037.

Koltuniewicz A.B., Drioli E., 2008. Membranes in clean technologies, theory and practice. Wiley-VCH.

Koltuniewicz A.B., 2010. Integrated membrane operations in various industrial sectors, In: Drioli E., Giorno L. (Eds.), Comprehensive membrane science and engineering. ELSEVIER, chapter 4.05.1.

Koltuniewicz A.B., 2011. Process engineering for sustainability, In: Encyclopedia of Life Support Systems. UNESCO EOLSS, chapter 6.34.7.1.

Modelski Sz., Kołtuniewicz A.B., Witek-Krowiak A., 2011. Kinetics of VOC absorption using capillary membrane contactor. Chem. Eng. J., 168, 1016-1023. DOI: 10.1016/j.cej.2011.01.075.

Kumar P.S., Hogendorn J.A., Feron P.H.M., Versteeg G.F., 2002. New absorption liquids for the removal of $\mathrm{CO}_{2}$ from diluted gas streams using membrane contactors. Chem. Eng. Sci., 57, 1639-1651. DOI: 10.1016/S00092509(02)00041-6.

Pagnanelli A.F., Beolchini F., Di Biase A., Veglio V., 2003. Effect of equilibrium models in the simulation of heavy metals biosorption in single and two-stage UF/MF membrane reactor systems. Biochem. Eng. J., 15, 2735. DOI: 10.1016/S1369-703X(02)00179-1.

Reed B.W., Siemens M.J., Cussler E.L., 1995. Membrane contactors, In: Noble R.D., Sern S.A. (Eds.), Membrane Separations Technology, Principles and Applications. ELSEVIER SCIENCE, Amsterdam, the Netherlands, Chapter 10.

Stankiewicz A., Moulin J.A., 2004. Re-engineering the chemical processing plant. Process intensification. Marcel Dekker, Inc., New York.

Witek A., Koltuniewicz A.B., Kurczewski B., Radziejowska M., Hatalski M., 2006. Simultaneous removal of phenols and $\mathrm{Cr}^{3+}$ using micellar-enhanced ultrafiltration process. Desalination, 191, 111-116. DOI: 10.1016/j.desal.2005.05.024.

Witek A., Szafran R.G., Koltuniewicz A.B., 2006. $p$-Cresol removal using a membrane contactor enhanced by the micellar solubilization, Desalination, 200, 575-577. DOI: 10.1016/j.desal.2006.03.453.

Witek-Krowiak A., Szafran R.G., Koltuniewicz A., 2009. Application of a membrane contactor for a simultaneous removal of p-cresol and $\mathrm{Cr}(\mathrm{III})$ ions from water solution, Desalination, 241, 91-96. DOI: 10.1016/j.desal.2007.11.083.

Yilmaza I., Kabay N., Bryjak M., Yüksela M., Wolska J., Koltuniewicz A.B., 2006. Submerged membrane-ionexchange hybrid process for boron removal. Desalination, 198, 310-315. DOI:10.1016/j.desal.2006.01.031. 